\title{
Fonoaudiologia educacional e autismo: defasagens e prejuízos da modalidade de ensino remoto em meio a pandemia da COVID-19 (2020 a 2021)
}

\author{
Educational speech therapy and autism: lags and losses of the remote teaching modality in the
} midst of the COVID-19 pandemic (2020 to 2021)

Logopedia educativa y autismo: rezagos y pérdidas de la modalidad de enseñanza a distancia en medio de la pandemia del COVID-19 (2020 a 2021)

\section{Resumo}

O profissional da fonoaudiologia educacional é responsável por prestar apoio aos pais e professores, principalmente no que se refere ao comprometimento da fala e da linguagem no processo de ensino-aprendizagem. Objetivou-se como essa pesquisa analisar as defasagens e prejuízos da modalidade de ensino remoto em meio a pandemia da COVID-19 de pessoas com Transtorno do Espectro Autista (TEA) para isso foi realizada uma Revisão Integrativa (RI) seguindo o que propõe Cooper (1984) a partir da literatura produzida na base Scientific Electronic Library Online (SciElo), as buscas resultaram em 11 pesquisas, compreendidas no biênio (2020 e 2021). Os resultados destacam o maior número de pesquisas relacionadas à Tecnologia Assistiva (TA) que possui característica interdisciplinar, englobando recursos, metodologias, estratégias entre outros. Outro aspecto apontado nas pesquisas foi as dificuldades de comunicação e interação social impostas pelo ensino remoto e isolamento social o que dificultou o os processos de inclusão escolar e digital. A família, a escola e as orientações de profissionais de saúde formaram o tripé que suprimiram as barreiras de comunicação, de verbalização e de linguagem oral provocadas pelo isolamento social e pela baixa interação desse público.

Palavras-chave: Fonoaudiologia educacional; Transtorno do Espectro Autista; Revisão integrativa.

\begin{abstract}
The educational speech therapy professional is responsible for providing support to parents and teachers, especially with regard to the impairment of speech and language in the teaching-learning process. The objective of this research was to analyze the delays and losses of the remote teaching modality amid the COVID-19 pandemic of people with Autistic Spectrum Disorder (ASD) for this, an Integrative Review (IR) was carried out following what Cooper proposes (1984) based on the literature produced in the Scientific Electronic Library Online (SciElo), the searches resulted in 11 researches, comprised in the biennium (2020 and 2021). The results highlight the largest number of researches related to Assistive Technology (AT), which has an interdisciplinary characteristic, encompassing resources, methodologies, strategies, among others. Another aspect pointed out in the researches was the difficulties in communication and social interaction imposed by remote education and social isolation, which made the processes of school and digital inclusion difficult. The family, the school and the guidance of health professionals formed the tripod. Which suppressed communication, verbalization and oral language barriers caused by social isolation and low interaction of this public.

Keywords: Educational speech therapy; Autistic Spectrum Disorder; Integrative review.
\end{abstract}

\section{Resumen}

El profesional de la terapia del habla educativa es responsable de brindar apoyo a los padres y maestros, especialmente con respecto a la discapacidad del habla y el lenguaje en el proceso de enseñanza-aprendizaje. El objetivo de esta investigación fue analizar los retrasos y pérdidas de la modalidad de enseñanza a distancia en medio de la pandemia del COVID-19 de personas con Trastorno del Espectro Autista (TEA) para ello, se realizó una Revisión Integrativa (RI) 
siguiendo lo propuesto por Cooper (1984) a partir de la literatura producida en la Scientific Electronic Library Online (SciElo), las búsquedas dieron como resultado 11 investigaciones, comprendidas en el bienio (2020 y 2021). Los resultados destacan la mayor cantidad de investigaciones relacionadas con la Tecnología Asistiva (TA), la cual tiene una característica interdisciplinaria, abarcando recursos, metodologías, estrategias, entre otros. Otro aspecto señalado en las investigaciones fueron las dificultades de comunicación e interacción social impuestas por la educación a distancia y el aislamiento social, que dificultaban los procesos de inclusión escolar y digital. La familia, la escuela y la guía de los profesionales de la salud formaron el trípode. Lo cual suprimió las barreras de comunicación, verbalización y lenguaje oral causadas por el aislamiento social y la baja interacción de este público.

Palabras clave: Logopedia educativa; Trastorno del espectro autista; Revisión integrativa.

\section{Introdução}

O ano é 2021. O mundo inteiro conectado através da tecnologia, surpreendidos por uma crise global. Estamos vivendo num isolamento social o que restringe a participação em atividades rotineiras. As pessoas se veem isoladas fisicamente, com sua mobilidade reduzida, devida a necessidade de evitar aglomerações para conter disseminação da doença que assola essa crise (Silva et al., 2021).

Repensar novos modos de se comunicar, conviver, estudar e trabalhar tem sido inerente a todos, nesse cenário pandêmico (Silva et al., 2021) e nesse sentido, a internet, os programas de comunicação e as mídias sociais passam a ser essenciais (Mendes et al., 2020, p. 35).

Nesse contexto o ensino remoto apresenta-se como uma realidade educacional desafiadora para todos e, em especial para alunos com Transtorno do Espectro Autista (TEA) e suas famílias. Entram em cena os desafios muitas vezes existentes da inclusão desses alunos que, somando-se à distância da escola, professores, interações e, por vezes terapias, passam a tornar mais complexo o Transtorno e suas singularidades.

Contudo, devido a pandemia do COVID -9, casas se tornam salas de aula e/ou "consultórios", e as telas dos computadores e celulares o único meio de uma possível interação desses alunos com docentes, outros alunos e demais profissionais de apoio (Barros \& Uhmann, 2020).

A inclusão ${ }^{1}$ de alunos com Transtorno do Espectro Autista (TEA) é uma discussão recorrente pela escola e demais profissionais extracurriculares. É direito do aluno garantido pela Lei 13.146/15 com relação a uma escolarização de igual condições como as demais pessoas, ou seja, envolve o acesso, permanência e desenvolvimento, além de profissionais voltados para a inclusão dentro da escola, a fim de que seus direitos sejam garantidos (Barros; Uhmann, 2020).

\subsection{O Transtorno do Espectro Autista (TEA) e o Ensino Remoto}

O Transtorno do Espectro Autista (TEA) está associado a uma alteração neurobiológica que provoca déficits persistentes na comunicação e na interação social, em múltiplos contextos, além da presença de padrões restritos e repetitivos de comportamento, interesses ou atividades, podendo acontecer em níveis de severidade distintos (APA, 2014).

Sua prevalência nos EUA, de acordo com o Centro de Controle e Prevenção de Doenças dos Estados Unidos - CDC (sigla em inglês), é de uma para cada 59 crianças na faixa etária dos 8 anos (Baio et al., 2018). No caso do Brasil, segundo a Sociedade Brasileira de Pediatria (SBP), não existem dados oficiais de prevalência; no entanto, nos últimos anos, sabe-se que as estimativas têm aumentado notavelmente, podendo ser resultado do aumento dos critérios diagnósticos e do desenvolvimento de meios de investigação mais adequados (SBP, 2019).

Sabe-se que o autismo apresenta diferentes combinações em sua genética, porém o grau de autismo decorre na prática em três graus, muito utilizados pelos profissionais, que segundo o DSM-V, (Diagnostic and Statistical Manual of Mental

\footnotetext{
${ }^{1}$ Trata-se de "um paradigma educacional fundamentado na concepção de direitos humanos, que conjuga igualdade e diferença como valores indissociáveis, e que avança em relação à ideia de equidade formal ao contextualizar as circunstâncias históricas da produção da exclusão dentro e fora da escola" (Brasil, 2008, p.5).
} 
Disorders), o TEA pode ser classificado como: Grau leve (Nível 1), necessidade de pouco apoio. Grau moderado (Nível 2), necessidade de apoio substancial. E o Grau severo (Nível 3), que precisa de necessidade de apoio muito substancial (Leite \& Dantas, 2020).

Existem inúmeras barreiras para a inclusão do aluno com TEA no Ensino Remoto. Infelizmente, as famílias ainda relatam haver muito preconceito e falta de empatia no ambiente escolar, além do despreparo de profissionais da educação.

Como destaca Barros e Uhmann (2020, p. 119):

Ademais, o baixo número de estudos disponíveis que versam sobre a visão parental acerca da inclusão de crianças com o TEA no ER demonstra que as famílias têm sido pouco consultadas sobre esse processo e, por conseguinte, têm tido uma participação menos ativa do que poderiam ter. Compreendemos que a ação colaborativa entre família e escola é de extrema relevância para que as barreiras da exclusão sejam superadas e haja contribuição no desenvolvimento e na qualidade de vida da criança no espectro. (Barros \& Uhmann, 2020, p. 119).

Desde a virada do século, no começo dos anos 2000, ouvimos que estamos vivendo a era digital. Já quase 21 anos depois, nos vemos cada vez mais imersos na tecnologia, agora mais do que nunca potencializadas pelo isolamento social. A internet hoje é sinônimo trabalho, facilidade, localização, informação, educação. São poucas as atividades que podemos fazer sem estar online.

Silva et al. (2021) reforçam que a tecnologia digital também pode alcançar as pessoas com deficiências, pois existem aplicativos, softwares e equipamentos que possibilitam a acessibilidade a informação, entretenimento, sociabilidade entre outros benefícios. Considerando o contexto da educação, a presença da tecnologia digital é uma alternativa de recurso que potencializa no ensino de alunos PAEE, que funciona com uma solução sobre as barreiras que esse público enfrenta no processo de aprendizagem.

O Estatuto da Pessoa com Deficiência, art. $3^{\circ}$, inciso IV traz a definição de barreira:

qualquer entrave, obstáculo, atitude ou comportamento que limite ou impeça a participação social da pessoa, bem como o gozo, a fruição e o exercício de seus direitos à acessibilidade, à liberdade de movimento e de expressão, à comunicação, ao acesso à informação, à compreensão, à circulação com segurança, entre outros. Enquanto as barreiras tecnológicas são aquelas que dificultam ou impedem o acesso da pessoa com deficiências às tecnologias (Brasil, 2015, p. 1).

Estas barreiras comprometem o acesso das pessoas com deficiência à educação, e atualmente, com a pandemia, as aulas começaram a ser transmitidas virtualmente, e as aulas presenciais foram paralisadas com intuito de minimizar o contato com o vírus SARS-Cov-2 e contágios em massa.

\subsection{Barreiras ou dificuldades do Ensino Remoto para o aluno com TEA}

No Quadro 1, a pesquisa realizada por Silva et al. (2021) expõe as dificuldades do aluno com TEA baseadas na literatura acadêmica que evidencia as especificidades desse público. 
Quadro 1: Dificuldades do Ensino Remoto para pessoas com TEA.

\begin{tabular}{|c|c|}
\hline $\begin{array}{c}\text { Tipo de Deficiência ou } \\
\text { transtorno de } \\
\text { desenvolvimento }\end{array}$ & Dificuldades no Ensino Remoto \\
\hline $\begin{array}{c}\text { Transtorno do Espectro do } \\
\text { Autismo }\end{array}$ & $\begin{array}{l}\checkmark \quad \text { Elas apresentam dificuldades na comunicação social, na linguagem receptiva e expressiva, } \\
\text { nas funções executivas e no tempo de atenção e concentração. } \\
\checkmark \quad \text { No ensino remoto, as atividades precisam levar em consideração os interesses do aluno, } \\
\text { preparar junto com a família um plano de trabalho, uma espécie de rotina. } \\
\checkmark \quad \text { Nas aulas síncronas é interessante que a turma esteja com o microfone desligado para não } \\
\text { gerar ruídos e incômodo sensorial, vídeos mais curtos e com bastante imagens e mapas } \\
\text { conceituais para assimilação de conceitos da área estudada, outra estratégia importante é } \\
\text { antecipar o que será trabalhado nas aulas seguintes. } \\
\checkmark \quad \begin{array}{l}\text { A escola também pode oferecer recursos estruturados para trabalhar as habilidades } \\
\text { necessárias, seja funcionais ou acadêmicas. }\end{array} \\
\checkmark \quad \begin{array}{l}\text { As atividades online/impressas devem conter enunciados em caixa alta, objetivos e claros; } \\
\text { uma atividade por página, com imagens e ilustrações a fim de facilitar a compreensão. }\end{array}\end{array}$ \\
\hline
\end{tabular}

Fonte: Silva et al (2021) - Adaptada.

As pessoas com TEA apresentam inúmeras dificuldades no que se refere ao acesso ao conhecimento escolar, e dentro do ensino remoto essas defasagens se amplificam (Silva et al., 2021). Mello (2004) reforça que para esses alunos todos os estímulos são de extrema importância, a interação social e atividades específicas e dirigidas às suas singularidades (vale lembrar: cada aluno com TEA é singular), entre outros, fazem/ou precisam fazer parte da escolarização desses alunos dentro das salas de aula regulares.

Em relação aos profissionais da Fonoaudiologia educacional, Ribas (2015) destaca que esses são capazes de proporcionar benefícios em prol de melhorias do desenvolvimento dos alunos que possuem necessidade especial na educação regular. Embora a regulamentação da Fonoaudiologia seja uma das mais recentes da área da saúde e sua atuação datada oficialmente a partir da década de 30, os conceitos podem ser encontrados em diferentes contextos históricos. Nascida primeiramente pela necessidade de avaliação e intervenção dos desvios encontrados na fala, desde então os profissionais que trabalhavam ajudando a corrigir essas alterações foram chamados de "logopedistas" ou 'reorganizadores de fala". Após a repercussão da atuação desses profissionais no decorrer do século, foi regulamentada a profissão de fonoaudiólogo em 09 de dezembro de 1981 com base na lei de número 6.965 que possibilitou esse profissional trabalhar de forma regular na pesquisa, avaliação e tratamento dos distúrbios da comunicação humana, a fonoaudiologia vem ganhando lugar de destaque na sociedade por ter uma área de atuação vasta, contanto hoje, de acordo com reconhecimento do conselho federal de fonoaudiólogia com 14 áreas bem definidas. Onde o profissional pode trabalhar tanto em ambientes clínicos e hospitalares, quanto em escolas e empresas.

Diante do atual cenário da educação, este trabalho tem como objetivos: a) Apontar aspectos relacionados à atuação dos profissionais de fonoaudiologia educacional e autismo, considerando as defasagens e prejuízos da modalidade de ensino remoto no contexto pandêmico. b) Identificar as dificuldades na comunicação, na linguagem, nas funções executivas e no tempo de atenção e concentração nos alunos com TEA no contexto do ensino remoto

Para responder a esses questionamentos foi realizado uma Revisão Integrativa (RI) Bienal (2020 e 2021) de pesquisas disponíveis na biblioteca virtual Scielo, como o intuito de responder a esses questionamentos.

\section{Metodologia}

Trata-se de uma revisão integrativa da literatura, a qual tem por finalidade reunir e sintetizar resultados de pesquisas acerca de um determinado tema, de maneira sistemática, contribuindo para o aprofundamento do conhecimento da área $\mathrm{e}$ permitindo conclusões acerca de uma questão específica (Mendes, Silveira \& Galvão, 2008). 
Para conduzir o caminho percorrido na Revisão Integrativa (RI), optou-se por trabalhar com as cinco fases do processo de elaboração proposta por Cooper (1984) como pode ser observado no Quadro 2.

Quadro 2: Etapas de Elaboração da Revisão Integrativa.

\begin{tabular}{|c|l|}
\hline Etapas & \multicolumn{1}{c|}{ Processos } \\
\hline Formulação do problema & $\begin{array}{l}\text { O que as pesquisas apontam sobre os impactos do ensino remoto para o aluno com } \\
\text { transtorno do espectro autista no que concerne às dificuldades na comunicação, na } \\
\text { linguagem, nas funções executivas e no tempo de atenção e concentração nos alunos? }\end{array}$ \\
\hline Coleta de dados & $\begin{array}{l}\text { As buscas serão realizadas na biblioteca virtual Scielo, banco de dados de revistas e } \\
\text { periódicos, anais de congressos do último Biênio (2020-2021). }\end{array}$ \\
\hline Avaliação dos dados & $\begin{array}{l}\text { Essa etapa tem grande relevância no estudo, pois é o momento de elucidar os principais } \\
\text { achados dos pesquisadores que já investigaram a temática. A coleta das pesquisas será } \\
\text { organizada com vistas a contemplar os achados mais relevantes nos estudos analisados, } \\
\text { mantendo uma padronização que possibilitou uma análise mais fidedigna. Elegeram-se } \\
\text { alguns elementos que foram tabulados em uma planilha a partir da leitura atenta de cada } \\
\text { pesquisa, sendo eles: identificação; características metodológicas dos estudos; aspectos } \\
\text { conceituais; resultados e generalizações; outros dados interessantes. }\end{array}$ \\
\hline $\begin{array}{c}\text { Análise e interpretação dos } \\
\text { dados }\end{array}$ & $\begin{array}{l}\text { Algumas questões centrais foram observadas, tanto no que se refere à parte teórica } \\
\text { conceitual quanto às questões metodológicas nas pesquisas publicadas, a exemplo das } \\
\text { diretrizes e dos princípios de inclusão e acessibilidade do aluno TEA. }\end{array}$ \\
\hline $\begin{array}{c}\text { Resultado da Análise dos } \\
\text { juízes }\end{array}$ & \begin{tabular}{l} 
Verificar se os artigos respondiam à pergunta de pesquisa. \\
\hline
\end{tabular} \\
\hline
\end{tabular}

Fonte: Cooper (1984).

Foram analisadas 11 pesquisas, que versavam sobre aspectos relacionados à fonoaudiologia educacional e autismo, considerando as defasagens e prejuízos da modalidade de ensino remoto no contexto pandêmico, por meio dos seguintes descritores: "Ensino Remoto + Autismo", "Fonoaudiologia + ensino remoto", "Fonoaudiologia + Educação Especial", "Fonoaudiologia + acessibilidade", "acessibilidade + Ensino remoto", “TEA + comunicação", "TEA + linguagem”.

Posteriormente, foram analisas as pesquisas que mais interessavam para o corpus desta revisão, usando como critérios de inclusão, a contribuição da pesquisa para esse estudo, a partir da leitura do material arrolado. Foram excluídas pesquisas que não se relacionavam com os objetivos desse estudo.

A partir dessa fase, foi possível encontrar evidências a serem utilizadas na elaboração dos resultados e discussões do estudo, para conseguinte análise e interpretação dos resultados realizada de forma descritiva.

\section{Resultados e Discussão}

No (Quadro 3) apresentamos a síntese dos estudos desta Revisão Integrativa, destacando-se as informações mais relevantes acerca de cada artigo analisado. 
Quadro 3 - Síntese dos estudos incluídos na Revisão Integrativa a partir das bases de dados ou periódicos no biênio (2020 2021)

\begin{tabular}{|c|c|c|c|}
\hline Ano & Autores & Título & Periódico/ Evento/Fonte \\
\hline 2020 & Barros \& Uhmann & $\begin{array}{l}\text { As (Im)Possibilidades do Ensino Remoto para o aluno com } \\
\text { Transtorno do Espectro Autista }\end{array}$ & $\begin{array}{l}\text { Anais do Seminário Nacional de } \\
\text { Educação Especial }\end{array}$ \\
\hline 2020 & Evêncio & $\begin{array}{l}\text { Ensino em tempos de Pandemia: Orientações para o Processo } \\
\text { de Ensino Inclusivo das Crianças com Autismo }\end{array}$ & Anais VII CONEDU \\
\hline 2020 & Nunes \& Dutra & $\begin{array}{l}\text { Ensino remoto para alunos do Atendimento Educacional } \\
\text { Especializado. }\end{array}$ & $\begin{array}{l}\text { Research, Society and } \\
\text { Development }\end{array}$ \\
\hline 2020 & Nunes & $\begin{array}{l}\text { Ensino Remoto Emergencial e Transtorno do Espectro } \\
\text { Autista: Uma análise sobre lives realizadas durante a } \\
\text { pandemia de COVID-19 }\end{array}$ & UFRGS \\
\hline 2020 & Souza \& Dainez & $\begin{array}{l}\text { Educação Especial e Inclusiva em tempos de pandemia: o } \\
\text { lugar de escola e as condições do ensino remoto emergencial }\end{array}$ & Práxis Educativa \\
\hline 2020 & Moraes et al. & $\begin{array}{l}\text { Percepções e desafios do ensino remoto para alunos do } \\
\text { espectro autista em tempos de pandemia no curso de ciências } \\
\text { biológicas. }\end{array}$ & $\begin{array}{l}\text { Anais do Seminário de } \\
\text { Atualização de Práticas Docentes }\end{array}$ \\
\hline 2021 & Dias, Santos \& Abreu & $\begin{array}{l}\text { Crianças com transtorno do espectro autista em tempos de } \\
\text { pandemia: contextos de inclusão/exclusão na educação } \\
\text { infantil. }\end{array}$ & Zero-a-Seis \\
\hline 2021 & $\begin{array}{l}\text { Albuquerque, Azevedo } \\
\text { \& Brandão }\end{array}$ & $\begin{array}{l}\text { O ensino de Matemática para alunos com Transtorno do } \\
\text { Espectro Autista durante a pandemia: um estudo de caso. }\end{array}$ & Indagatio Didactica \\
\hline 2021 & Ferreira et al. & $\begin{array}{l}\text { Material Didático Adaptado frente ao Ensino Remoto: Uma } \\
\text { resposta inovadora através da linguagem. }\end{array}$ & $\begin{array}{l}\text { Anais Educação em Foco: } \\
\text { IFSULDEMINAS } \\
\end{array}$ \\
\hline 2021 & Monteiro et al. & $\begin{array}{l}\text { O ensino na pandemia: uma análise comparativa do } \\
\text { dispositivo autista de inclusão (dai) como nova proposta para } \\
\text { a família com criança com transtorno do espectro autista. }\end{array}$ & $\begin{array}{l}\text { BIUS-Boletim Informativo } \\
\text { Unimotrisaúde em } \\
\text { Sociogerontologia } \\
\end{array}$ \\
\hline 2021 & Candido et al. & $\begin{array}{l}\text { Aluno com o transtorno de espectro autista em tempos de } \\
\text { pandemia: uma revisão sistemática }\end{array}$ & $\begin{array}{c}\text { Seminário Nacional e Seminário } \\
\text { Internacional Políticas Públicas, } \\
\text { Gestão e Práxis Educacional }\end{array}$ \\
\hline
\end{tabular}

Fonte: Dados da pesquisa.

Abaixo no (Quadro 4) foram disponibilizadas as principais congruências apresentadas pelos autores no decorrer de suas pesquisas, nas quais realizou-se a integralização de tais resultados a partir de aspectos convergências e especificando essas vertentes por termos escolhidos para direcionar os achados mais importantes, conforme as orientações apontadas como eixo centralizador das pesquisas analisadas.

Quadro 4 - Integralização das pesquisas conforme resultados mais relevantes para temática $(2020$ - 2021).

\begin{tabular}{|c|l|l|}
\hline $\begin{array}{c}\text { Temas } \\
\text { Compartilhados }\end{array}$ & \multicolumn{1}{|c|}{ Autores } & \multicolumn{1}{|c|}{ Discussões implementadas } \\
\hline $\begin{array}{c}\text { Tecnologia } \\
\text { Assistiva }\end{array}$ & $\begin{array}{l}\text { Barros \& Uhmann (2020); Nunes } \\
\text { (2020); Moraes et al. (2020); Nunes \& } \\
\text { \&utra (2020); Albuquerque, Azevedo } \\
\text { \& Brandão (2021); Monteiro et al. }\end{array}$ & $\begin{array}{l}\text { A contribuição das tecnologias assistivas para } \\
\text { letramento e interação social de pessoas com } \\
\text { Transtorno do Espectro Autista. }\end{array}$ \\
\hline $\begin{array}{c}\text { Desenvolvimento } \\
\text { (comunicação \& } \\
\text { linguagem) }\end{array}$ & $\begin{array}{l}\text { Dias, Santos \& Abreu (2021); Ferreira } \\
\text { et al. (2021) }\end{array}$ & $\begin{array}{l}\text { Déficits na comunicação e interação social, } \\
\text { dificuldades no estabecimento de uma simples } \\
\text { conversa e no compartilhamento de emoções, } \\
\text { interesses; comprometimentos ou completa } \\
\text { ausência nas expressões faciais. }\end{array}$ \\
\hline Inclusão & $\begin{array}{l}\text { Evêncio (2020); Souza \& Dainez } \\
(2020)\end{array}$ & $\begin{array}{l}\text { Processos de inclusão escolar e digital no contexto } \\
\text { do ensino remoto. }\end{array}$ \\
\hline
\end{tabular}

Fonte: Dados da pesquisa.

Barros e Uhmann (2020) em sua pesquisa apontaram que o ensino remoto é uma realidade educacional desafiadora para todos e, em especial para alunos com Transtorno do Espectro Autista (TEA) e suas famílias. Entram em cena os desafios muitas 
vezes existentes da inclusão desses alunos que, somando-se à distância da escola, professores, interações e, por vezes terapias, passam a tornar mais complexo o Transtorno e suas singularidades. Os resultados evidenciaram a escassa relação entre escola e família (que por vezes já existia, mas que agora agravou-se), as dificuldades da família em gerenciar e desenvolver atividades pedagógicas de acordo com as singularidades necessárias às especificidades das alunas e o reconhecimento do avanço das limitações e comprometimentos do TEA devido o afastamento da escola e/ou pausa de atendimentos - fato que nos leva a reconhecer a importância (mesmo que com barreiras ainda existentes) do processo de inclusão de alunos com TEA em escolas regulares.

Serra (2006) reforça que o acompanhamento pedagógico específico da escola é de extrema importância para seu aprendizado e desenvolvimento para alunos com TEA, nesse sentido:

(...) a convivência compartilhada da criança com autismo na escola, a partir da sua inclusão no ensino comum, possa oportunizar os contatos sociais e favorecer não só o seu desenvolvimento, mas o das outras crianças, medida em que estas últimas convivam e aprendam com as diferenças." (Camargo \& Bosa, 2009, p. 68).

Evêncio (2020) investigou questões de ensino em tempos de pandemia. Nesse cenário, se faz relevante investigar o processo de inclusão escolar de crianças com autismo com objetivo de conhecer e propor orientações direcionadas as famílias, professores e gestão escolar que favoreçam a inclusão destas crianças. Para tanto, participaram 06 profissionais clínicos como psicólogos, psicopedagogos, fonoaudiólogos, além de especialistas em educação especial. Foi possível constatar que as orientações priorizam a saúde mental das crianças, devendo esse ser o objetivo primordial das instituições e famílias. O estudo cumpriu com objetivo proposto e identificou questões para estudos futuros.

$\mathrm{O}$ autor ainda orienta que qualquer atividade deve respeitar os limites da criança primando pela segurança em todos os momentos. Os exemplos foram para demonstrar que ações do cotidiano podem ser estratégias de estimulação, desde que com ponderação na comunicação, nas solicitações e no modelo porque as crianças têm maior facilidade em aprender pela imitação, pelo incentivo e no clima colaborativo, uma estratégia de amenizar os sintomas que interferem diretamente na aprendizagem deles (Evêncio, 2020).

A presente realizada por Nunes (2020) configura como uma análise audiovisual, com foco em 10 lives que debatem os impactos da pandemia de COVID-19 na vida escolar de crianças autistas e deficientes e quais as adaptações possíveis para garantir a inclusão dessas crianças nesse novo modelo de aulas. As transmissões foram realizadas por diferentes especialistas do campo da educação, psicologia, fonoaudiologia, direito e áreas afins. Durante a pandemia, investigou-se, de forma mais aprofundada, o impacto dessa mudança repentina para as crianças no Transtorno do Espectro Autista (TEA). O objetivo central visa analisar o que educadoras/es e outros profissionais sugeriram/sugerem como adaptações possíveis a fim de incluir o ERE na rotina escolar de alunos no TEA e como as professoras podem contribuir neste processo. Os resultados apontam que é fundamental readaptar as práticas pedagógicas para todas as crianças, centralmente para as crianças deficientes, estreitar os laços com as famílias e buscar melhores formas de garantir que o aluno tenha suas rotas de aprendizagem respeitadas e potencializadas nesse momento.

Souza e Dainez (2020) analisaram as condições de realização do ensino remoto emergencial direcionadas a um aluno com Transtorno do Espectro do Autismo, matriculado no $4^{\circ}$ ano do Ensino Fundamental I. O estudo de caráter exploratório partiu da análise de um relato de experiência e teve como ancoragem a perspectiva histórico-cultural do desenvolvimento humano, em especial a ideia de que as condições sócio-histórico-culturais e políticas são fonte de desenvolvimento da atividade psíquica. Os resultados evidenciam o lugar da escola na vida do aluno e apontam para o papel dessa instituição social como espaço coletivo de resistência político-pedagógica e mediadora dos processos de humanização.

Os autores ainda destacaram que o fechamento das escolas fez-nos perceber a falta do convívio, dos barulhos, do contato 
físico, do movimento do corpo, das interações, dos processos de socialização, da participação em uma coletividade de forma mais efetiva. Nessa ausência, manifesta-se o reconhecimento do papel social dessa instituição, sobretudo a sua importância na formação humana. Na permanência do reconhecimento, a escola configura-se como espaço coletivo de resistência políticopedagógica para o enfrentamento de uma ideologia que tenta rebaixar a produção do conhecimento, particularmente no campo das ciências humanas (Souza \& Dainez, 2020).

Moraes et al. (2020) em sua pesquisa analisou as definições e compreensões atuais do (TEA), assim como a definição de muitas das terminologias utilizadas tanto no contexto médico quanto no senso comum, e refletir sobre seus desdobramentos diante da perspectiva histórica, biológica e social da neurodiversidade humana, bem como, avaliar os desafios desde o surto da COVID-19 no Brasil, as mudanças que ocorrem no enfrentamento à pandemia como o isolamento social e a exequibilidade do ensino remoto. De um modo geral, o novo papel assumido pelos professores em época de pandemia manterá a execução das atividades docentes e uma atenção representativa aos alunos TEA. É possível a utilização de tecnologia para orientar um treino de habilidades comportamentais e de ensino aprendizagem à distância. Para isso, os professores e demais colegas de turma deverão ficar sob o controle final de um monitoramento partilhado, no qual as duas pontas desse processo interventivo e de estímulos possam acompanhar todo o processo descrito nas atividades remotas com utilização de metodologias ativas e visuais.

A pesquisa realizada por Albuquerque, Azevedo \& Brandão (2021) trata sobre o ensino de matemática para estudantes com Transtorno do Espectro Autista (TEA) com o objetivo de conhecer de que forma aconteceu o ensino de Números e Quantidades para educandos com TEA nesse período de aula remota na referida escola. O embasamento teórico utilizado para as discussões se ancorou nas definições e características do TEA, na Educação Matemática para um sistema inclusivo, no ensino remoto e no ensino de Matemática para alunos com TEA. Ao responder às indagações, a professora expôs que as ferramentas digitais utilizadas para ministrar as aulas foram: WhatsApp e Google Meet e que as estratégias para a realização das atividades foram desenvolvidas com a ajuda dos familiares. Um ponto que mereceu destaque foi a parceria e dedicação da família para que esse ensino acontecesse e os filhos pudessem participar das aulas. Conclui-se que, de modo geral, o ensino só foi possível pela efetiva e significativa parceria entre o professor do AEE e a família.

Dessa forma o ensino em geral, para alunos especiais, torna-se efetivo e com significado quando existe uma parceria entre os professores do AEE, o professor do ensino regular e a família. Pois, foi perceptível que essa parceria constrói e desenvolve estratégias pensando diretamente no aluno, para assim, atingir certas habilidades, como: atrair atenção, estimular a interação e a comunicação entre eles, mesmo que não verbal, possibilitando, então, a construção da aprendizagem.

Ferreira et al. (2021) apontou que o uso de materiais adaptados atua na educação como um ato que promove tentativas de educação inclusiva, pois visa ofertar as condições para que alunos com necessidades especiais possam participar das atividades escolares. Entretanto, muitas escolas carecem desse tipo de material, e a responsabilidade de confecção fica a cargo do corpo docente, do qual muitos professores se sentem despreparados por não conseguirem confeccionar esse tipo de material. Nesse contexto, o objetivo deste trabalho consiste em relatar, através de um relato de caso, a importância desse material para o ensino aprendizagem de um aluno com autismo. A pesquisa ainda apontou que o ensino da linguagem, aos autistas, deve ser desenvolvido em ambientes naturais da criança, pois ele facilita uma rotina na qual eles respondem melhor aos estímulos.

Vygotsky (1997), em seus estudos sobre defectologia, defendeu a importância da mediação no processo de aprendizagem, e tais trocas exercem funções importantes para o desenvolvimento, a aprendizagem e a regulação da criança com autismo.

Monteiro et al. (2021) apresentaram os resultados de uma investigação sobre as representações de famílias de crianças com Transtorno do Espectro Autista (TEA) diante do novo contexto de isolamento social e do ensino remoto provocado pela pandemia da COVID-19 e analisar comparativamente, uma nova proposta metodológica sobre um dispositivo capaz de acompanhar o processo de ensino aprendizagem da criança com TEA, no ambiente familiar, seguindo as orientações do 
profissional de saúde. Os resultados apontam que há desafios no ensino remoto, principalmente quando ele se direciona a alunos com TEA, contudo, defendemos a necessidade da criança seguir em rotina similar à da escola, coisa que o dispositivo atua mesmo em período de isolamento social, para isso, é preciso que as famílias sigam somando esforços para auxiliarem seus filhos neste novo cenário e, que a escola, os professores, os profissionais de saúde e a família continuem buscando maneiras de se reinventarem, com ações inclusivas, cujo foco seja a manutenção da proximidade nas relações entre aluno/professor/escola/ Profissionais e família.

Considerando o extenso período pandêmico e as publicações já existentes na área, surge a necessidade de estudos e investigações científicas que proporcionem direcionamento aos professores e familiares quanto à educação para o desenvolvimento escolar de alunos com TEA. Candido et al. (2021) realizou uma revisão sistemática de literatura em revistas científicas da área educacional. Para coleta de dados utilizou-se dois descritores, sendo eles, pandemia e na sequência o descritor autista. Dentre as revistas publicadas, somente um artigo que aborda o tema sobre o aluno com o transtorno de espectro autista na pandemia foi encontrado, fato que evidencia a necessidade de novas publicações na área, para que estas, proporcionem subsídios acadêmicos na atuação educacional e orientação destes alunos hoje e no futuro pós-pandemia.

Candido et al. (2021) relataram a necessidade de novas pesquisas na área, levando em conta o atual cenário de distanciamento social e a utilização de novos recursos tecnológicos para a realização de aulas remotas, mantendo o distanciamento social recomendado como contenção da disseminação do vírus, tendo em vista, que tais recursos podem interferir no desenvolvimento cognitivo e social dos alunos com o transtorno de espectro autista, mas que também poderão continuar sendo utilizados como aporte a educação após o período pandémico pela escola regular.

Nunes \& Dutra (2020) em seu trabalho traçaram um panorama de como os professores do Atendimento Educacional Especializado (AEE) da rede municipal de ensino de Uruguaiana/RS vem desenvolvendo esse serviço no Ensino Remoto. Com esse intuito foi desenvolvido um questionário aplicado a 09 professores de AEE do município. Os resultados apontaram que os professores pesquisados possuem formação adequada, bem como tem realizado inúmeros cursos de capacitação via ensino à distância. Segundo os professores existem entre 11 e 24 alunos em cada escola necessitando de atendimento com as mais variadas deficiências. As atividades do AEE vêm sendo realizadas remotamente através de recursos de tecnologias digitais/impressa e o auxílio dos familiares dos estudantes. A efetividade desse atendimento, depende de diferentes fatores como: o tipo de necessidade especial, a capacidade de interação do aluno com as mídias digitais/impressas e o comprometimento familiar.

Dias, Santos \& Abreu (2021) reforçaram o impacto provocado pela pandemia da COVID-19 nas rotinas e modos de vida de bebês e crianças pequenas e suas famílias, sobretudo, em função do fechamento das instituições de educação infantil, ocasionando novas dinâmicas de sociabilidade e importantes mudanças na ação educativa. Considerando a complexidade dessas alterações e a especificidade do trabalho educativo com crianças com Transtorno do Espectro Autista, essa pesquisa refletiu a relação de inclusão/exclusão dessas crianças, mediante análise de elementos teóricos que problematizam a ação educativa, à luz dos pressupostos teóricos da educação inclusiva. $\mathrm{O}$ estudo ainda apontou que crianças com TEA necessitam de atenção às suas peculiaridades, dentre elas, as de natureza interativa e que os limites colocados pela pandemia interrogam as possibilidades educativas e apontam para a construção de estratégias metodológicas individualizadas que favoreçam o desenvolvimento dessas crianças.

Alguns aspectos importantes destacados por Dias, Santos \& Abreu (2021, p.115) reforçam e justificam os objetivos apresentados nessa pesquisa, a saber:

Características marcantes de crianças com TEA indicam comprometimento da comunicacão, com registros de que muitas crianças não conseguem verbalizar ou ainda fazem uso dessa linguagem oral de forma limitada. Agrega-se ainda, a tendência ao isolamento social e apego a rotinas, tendo estas últimas como algo, muitas vezes, inflexíveis, causando graus preocupantes de ansiedade quando interrompidas (grifo nosso). 
Ademais, o DSM-5, retrata os déficits na comunicação e interação social em diversos contextos, que perpassam desde dificuldades no estabelecimento de uma simples conversa e no compartilhamento de emoções, interesses; comprometimentos ou completa ausência nas expressões faciais; até dificuldades em criar laços de amizades, apresentando desinteresse por seus pares.

Santos e Nascimento (2021) destacam as contribuições da fonoaudiologia no ambiente escolar em prol de uma maior inclusão de alunos com necessidades especiais ressaltam-se a identificação de estudantes que possuem dificuldades na comunicação e que sofrem com problemas de comunicação, e consequentemente resultando em problemas referentes a socialização, informando desse modo os professores sobre o modo de lidarem com esse corpo discente em sala de aula.

Por meio da fonoaudiologia é capaz de haver um maior desenvolvimento das diversas modalidades de linguagem, em especial a oral e a escrita, além de contribuir em prol da motricidade orofacial, de aspectos referentes a voz e da audição, sendo os fonoaudiólogos auxiliares diretos dos responsáveis pelo processo de ensino aprendizagem e contribuindo com as dificuldades enfrentadas pelos familiares dos discentes que possuem dificuldades de comunicação (Santos \& Nascimento, 2021, p. 11).

As autoras ainda apontam a elaboração de programas e políticas pedagógicas direcionadas ao atendimento de forma individual, conforme a especificidade de cada aluno.

Ferreira et al. (2021) apontaram como o uso de materiais adaptados atua na educação, pois visa ofertar as condições para que alunos com necessidades especiais possam participar das atividades escolares. Entretanto, muitas escolas carecem desse tipo de material, e a responsabilidade de confecção fica a cargo do corpo docente, do qual muitos professores se sentem despreparados por não conseguirem confeccionar esse tipo de material. Nesse contexto, o objetivo deste trabalho consiste em relatar, através de um relato de caso, a importância desse material para o ensino aprendizagem de um aluno com autismo.

A pesquisa ainda destacou que o ensino da linguagem, aos autistas, deve ser desenvolvido no ambiente natural da criança, pois ele facilita uma rotina na qual eles respondem melhor aos estímulos. O estudo ainda apontou que o material adaptado favoreceu o desenvolvimento da leitura e estimulou a linguagem.

\section{Considerações Finais}

Embora a dinâmica social tenha se alterado em virtude de uma pandemia de ordem global, o ensino remoto apresentouse como uma condição imposta. E é nesse cenário que a inclusão escolar se torna algo de extrema importância tanto para esses alunos como para os demais, pois os auxilia em desenvolver tanto aspectos cognitivos quanto aspectos afetivos.

No contexto de isolamento social, a falta de interação interpessoal presencial provoca uma avalanche de adaptações curriculares a fim de que a aprendizagem e o desenvolvimento sejam garantidos. Diante dessa demanda instaurada, realizar uma revisão integrativa sobre essa temática, possibilitou identificar um cenário de tendencias e avanços. O papel da família como peça central do processo educativo mostrou-se desafiador, principalmente para os alunos com TEA, uma vez que essas crianças necessitam de olhares, cuidados e estímulos específicos nos campos das interações sociais, comunicação e comportamentos.

As pesquisas de um modo geral destacam o papel do mediador, da mediação para dar continuidade ao processo de ensino-aprendizagem afim de suprimir as barreiras de comunicação, de verbalização e de linguagem oral provocadas pelo isolamento social e baixa interação.

A integração das pesquisas de uma forma geral apontou carência de pesquisas específicas sobre essa temática, em virtude de o cenário pandêmico ainda estar acontecendo. Um outro aspecto a se considerar é a intersetorialidade, a atuação conjunta dos profissionais de saúde, escola e família no processo de ensino, aprendizagem e inclusão de alunos com autismo no modelo de ensino remoto. 


\section{Referências}

Camargo, S. P. H., \& Bosa, C. A. (2009). Competência social, inclusão escolar e autismo: revisão crítica da literatura. Psicologia \& sociedade, $21,65-74$.

Santos, M. P. dos, \& Paulino, M. M. (2006). Inclusão em educação: culturas, políticas e práticas. Cortez.

American Psychiatric Association. (2014). DSM-5: Manual diagnóstico e estatístico de transtornos mentais. Artmed Editora.

Albuquerque, R. M., de Azevedo, I. F., \& Brandão, J. C. (2021). O ensino de Matemática para alunos com Transtorno do Espectro Autista durante a pandemia: um estudo de caso. Indagatio Didactica, 13(3), 247-262.

Brasil. (2008) Ministério da Educação. Política Nacional de Educação Especial na perspectiva da Educação Inclusiva. MEC; SEEP.

Brasil. (2015) Lei Brasileira de Inclusão da Pessoa com Deficiência (Estatuto da Pessoa com Deficiência). Lei nº13. 146 , de 6 de julho de 2015.

Baio, J., Wiggins, L., Christensen, DL, Maenner, MJ, Daniels, J., Warren, Z., ... \& Dowling, NF (2018). Prevalência de transtorno do espectro do autismo entre crianças de 8 anos - rede de monitoramento de autismo e deficiências de desenvolvimento, 11 locais, Estados Unidos, 2014. MMWR Surveillance Summaries, 67 (6), 1.

Barros, L. da Cruz, \& Uhmann, S. (2020). As (Im) Possibilidades do Ensino Remoto para o Aluno com Transtorno do Espectro Autista. Anais do Seminário Nacional de Educação Especial e do Seminário Capixaba de Educação Inclusiva, 3(3).

Candido, E. A. P., Assunção, M. M., Cunha, J. J. D., \& Carneiro, R. U. C. (2021). Aluno com o transtorno de espectro autista em tempos de pandemia: uma revisão sistemática. Seminário Nacional e Seminário Internacional Políticas Públicas, Gestão e Práxis Educacional, 8(9).

Cooper, H. M. (1988). The integrative research review: a systematic aproach. The integrative research review: A systematic aproach, $144-144$.

Camargo, S. P. H., \& Bosa, C. A. (2009). Competência social, inclusão escolar e autismo: revisão crítica da literatura. Psicologia \& sociedade, $21,65-74$.

Dias, A. A., Santos, I. S., \& de Abreu, A. R. P. (2021). Crianças com transtorno do espectro autista em tempos de pandemia: contextos de inclusão/exclusão na educação infantil. Zero-a-Seis, 23(Especial), 101-124.

Evêncio, kátia M. de moura. (2020). Ensino em tempos de pandemia: orientações para o processo de ensino inclusivo das crianças com autismo. In: VII Cogresso Nacional de Educação - CONEDU, 2020, on-line. Anais VII CONEDU - Edição Online.

Ferreira, L. F., Costa, A. S., Simões, C. C., \& Cardoso, D. F. (2021). Material Didático Adaptado Frente Ao Ensino Remoto: Uma resposta inovadora através da linguagem. Anais Educação em Foco: IFSULDEMINAS, 1(1).

da Silva Leite, C. M., \& Dantas, S. M. (2020). A Afetividade no Desenvolvimento Cognitivo do Aluno com Transtorno de Espectro Autista-TEA/Affectivity in the Cognitive Development of the Student with Autistic Spectrum Disorder-TEA. ID on line REVISTA DE PSICOLOGIA, 14(53), 41-51.

Mello, A. M. S. (2001). Autismo: guia prático.

Mendes, A., Vinagre, A. B., Amorim, A., Chaveiro, E., Machado, K., Vasconcellos, L. C. F. D., \& Gertner, S. (2020). Diálogos sobre acessibilidade, inclusão e distanciamento social: territórios existenciais na pandemia.

Mendes, K. D. S., Silveira, R. C. D. C. P., \& Galvão, C. M. (2008). Revisão integrativa: método de pesquisa para a incorporação de evidências na saúde e na enfermagem. Texto \& contexto-enfermagem, 17, 758-764.

Monteiro, C. G., Silva, T. D. S. A., Rossi, R., Monteiro, F. C. B., \& Lira, A. B. P. (2021). O ensino na pandemia: uma análise comparativa do dispositivo autista de inclusão (dai) como nova proposta para a família com criança com transtorno do espectro autista. BIUS-Boletim Informativo Unimotrisaúde em Sociogerontologia, 26(20), 1-16.

Nunes, J. M. (2020). Ensino remoto emergencial e transtorno do espectro autista: uma análise sobre lives realizadas durante a pandemia de COVID-19.

Nunes, R. C. A., \& Dutra, C. M. (2020). Ensino remoto para alunos do Atendimento Educacional Especializado. Research, Society and Development, 9(11), e64291110060-e64291110060.

Peixoto, J. C., Moraes, C. G., Peres, P. H. A., do Vale Lima, R. E., \& da Silva Braz, V. (2020). Percepções E Desafios Do Ensino Remoto Para Alunos Do Espectro Autista Em Tempos De Pandemia No Curso De Ciências Biológicas. Anais do Seminário de Atualização de Práticas Docentes, 2(2).

de Souza, F. F., \& Dainez, D. (2020). Educação Especial e Inclusiva em tempos de pandemia: o lugar de escola e as condições do ensino remoto emergencial. Práxis Educativa (Brasil), 15, 1-15.

dos Santos, M. P., \& Paulino, M. M. (2006). Inclusão em educação: culturas, políticas e práticas. Cortez.

da Silva, I. R., Freitas, T. N., de Araújo, N. F. M., da Silva Sousa, D. L., de Araújo Júnior, M. A., Medeiros, A. M., \& Silva, R. S. (2021). Acessibilidade digital em tempos de ensino remoto. Research, Society and Development, 10(4).

Ribas, A. (2015). Atuação fonoaudiológica nas escolas. Fonoaudiologia e Educação: uma parceria necessária.

Santos, PC e Nascimento, MFS. (2021). A colaboração da Fonoaudiologia educacional em prol de um sistema educacional igualitário. Pesquisa, Sociedade e Desenvolvimento, 10 (1), e3810111432.

Vygotsky, L. S. (1997). Obras escogidas: fundamentos de defectología (Vol. 5). Visor. 